\title{
Age determination of the adult blow fly Lucilia sericata (Diptera: Calliphoridae) through quantitative pteridine fluorescence analysis
}

\author{
Ronja Estévez Dimitrov ${ }^{1}$ (D) Jens Amendt ${ }^{1} \cdot$ Florian Rothweiler $^{2} \cdot$ Richard Zehner $^{1}$
}

Accepted: 28 July 2020 / Published online: 11 September 2020

(C) The Author(s) 2020

\begin{abstract}
Determination of a minimal postmortem interval via age estimation of necrophagous diptera has been restricted to the juvenile stages and the time until emergence of the adult fly, i.e. up until 2-6 weeks depending on species and temperature. Age estimation of adult flies could extend this period by adding the age of the fly to the time needed for complete development. In this context pteridines are promising metabolites, as they accumulate in the eyes of flies with increasing age. We studied adults of the blow fly Lucilia sericata at constant temperatures of $16^{\circ} \mathrm{C}$ and $25^{\circ} \mathrm{C}$ up to an age of 25 days and estimated their pteridine levels by fluorescence spectroscopy. Age was given in accumulated degree days (ADD) across temperatures. Additionally, a mock case was set up to test the applicability of the method. Pteridine increases logarithmically with increasing ADD, but after 70-80 ADD the increase slows down and the curve approaches a maximum. Sex had a significant impact $\left(p<4.09 \times 10^{-6}\right)$ on pteridine fluorescence level, while body-size and head-width did not. The mock case demonstrated that a slight overestimation of the real age (in ADD) only occurred in two out of 30 samples. Age determination of $L$. sericata on the basis of pteridine levels seems to be limited to an age of about $70 \mathrm{ADD}$, but depending on the ambient temperature this could cover an extra amount of time of about 5-7 days after completion of the metamorphosis.
\end{abstract}

Keywords Forensic entomology $\cdot$ Post mortem interval $\cdot$ Accumulated degree days $\cdot$ Age determination $\cdot$ Pteridine

\section{Introduction}

Forensic entomology investigates insects and other arthropods as a part of legal cases, where one of its most important tasks is estimating the period of time since death or placement of a body [1]. Especially in cases where there is advanced decomposition of a body, insects may be the only way to draw conclusions about the possible time of death, which is highly relevant in homicides as well as in other scenarios. In times of an ageing population in Western and other countries and an increasing number of older singles or single households in general $[2,3]$, finding bodies in an advanced stage of

Ronja Estévez Dimitrov

ronjaestevez@gmail.com

1 Institute of Legal Medicine, University Hospital Frankfurt, Goethe-University, Kennedyallee 104, 60596 Frankfurt am Main, Germany

2 Institute of Medical Virology, University Hospital Frankfurt, Goethe-University, Paul-Ehrlich-Str.40, Frankfurt am Main 60596, Germany decomposition and undetected for a longer period of time, especially indoors, is becoming more common. In fact, $85 \%$ of the bodies with insect infestation examined at our institute within the last 2 years were found indoors (unpublished data). Even though the majority of these cases did not involve homicides, it is still good practice to make an accurate statement about the time of death. Knowing the date of death helps to quickly make an initial assessment of what happened.

The time between death and discovery of the body is known as the post-mortem interval (PMI). Since external circumstances can delay the arrival of necrophagous insects and their subsequent colonization of a body, the period of time that is determined by entomological investigations is therefore referred to as a minimum post-mortem interval $\left(\mathrm{PMI}_{\min }\right)$. One standard to determine the $\mathrm{PMI}_{\min }$ is to identify the insect species found on the body and their state of development or age, which corresponds with the time they need to reach this state in given environmental conditions beginning with the colonization of the body [4].

The most common insects found on dead bodies are necrophagous flies and their offspring - in cases where the PMI exceeds $72 \mathrm{~h}$, they are considered the most accurate tools to 
determine $\mathrm{PMI}_{\min }[5,6]$. Blow flies (Diptera: Calliphoridae) are of special importance since they are not only omnipresent but usually also the first at the site [7].

Depending on temperature and species, blow flies develop over a period of 2-4 weeks after oviposition until the fly has completed its metamorphosis and hatched [8]. Various landmarks of development such as eggs, the growing size of larvae, their stage of development and the time of pupariation as well as the hatching of the adult fly allow conclusions about the time of oviposition and hence about the $\mathrm{PMI}_{\text {min }}$.

Aging of adult flies that remain at the scene on the body in question after finishing their development might open a new door of $\mathrm{PMI}_{\min }$ estimation, especially when it comes to indoor investigations where hatched flies have trouble leaving the room due to closed conditions [6]. So far, there have been different approaches for age grading adult flies, but they are often time consuming, imprecise and of limited use [9]. The most common procedure is the estimation of age based on the stage of development of the ovaries of female flies. Studies with different species such as tsetse flies Glossina spp. or forensically relevant blow flies Lucilia cuprina [9] and L. sericata [10] achieved good results, but also reported numerous limitations of the method, such as interference due to protein uptake, availability of oviposition site and mating status, as well as strong temperature sensitivity and difficulties in determining the number of previous ovarian cycles. In the field of somatic changes, there are different approaches, such as the evaluation of qualitative and quantitative differences in cuticular hydrocarbons $[11,12]$. Studies on the blow flies L. sericata, Calliphora vicina [13] and the mosquito Aedes aegypti [14] show promising results, but also a strong influence of temperature, humidity and artificial laboratory conditions on the production and presence of cuticular hydrocarbons and the reproducibility still has to be investigated. Counting bands on muscle apodemes or the layers in the cuticle as a measure of the age of young adult insects $[9,15]$ is a further method but is limited to the teneral stage. Temperature, and especially temperature fluctuations between night and day, showed a strong impact on layer growth. Age determination by mechanical damage of the insect investigates things like wing fray as a measure of age. Of all the methods mentioned so far, the latter is the oldest but also the most inaccurate method of age determination, as wing damage does not just increase with age, but is caused or impacted by very local and unique environmental factors such as predator attacks, or frequency of wing movement, i.e. flight activity $[9,16]$.

Another method of using age dependent physical changes to help determine a specimens age is to correlate the age of an adult fly with the pteridine level in its eyes, measured by fluorescence intensity [9]. Studies on blowflies and house flies C. vicina [8], Musca domestica [17] and Chrysomya megacephala [18] showed a clear increase of pteridine with age. While sex and temperature, in addition to age, show a clear influence on the pteridine level during fly aging $[10,17-20]$, diet [10,17-19] and light conditions $[17,20]$ do not.

Pteridines were named after they were discovered in wing pigments (Greek "ptera") of pierid butterflies and were observed to accumulate in the eyes of flies with increasing age [21]. They are substances derived from the pyrimidinepyrazine ring and seem to be present in all living organisms, with insects appearing to contain them in higher concentrations than most others. They have many varied functions and roles, including being described as important co-factors in cell metabolism and as signal molecules [22], protective antioxidants [23], UV absorbing filters, pigments for protection, recognition or communication $[21,24]$ and even as a way of endogenous nitrogen excretion for some insects [22]. Their characteristic of absorbing UV light appears to be their most important role in compound eyes, as increased light sensitivity can be observed in flies without pteridine [25]. Pteridines show a constant and extended linear correlation between the intensity of fluorescence and the amount of substance present, and the high sensitivity of the method is suitable for even small sample sizes [21, 26].

Age determination by pteridine levels has been investigated in several insects (including many necrophagous flies), such as Boettcherisca peregrina [6], C. vicina [8], Ch. bezziana [19], Ch. megacephala [18, 27], Cochliomyia macellaria [27], M. domestica [17], Phormia regina [27], and L. sericata [10]. The latter is one of the most frequently encountered species of necrophagous flies in Western Europe [28-30].

The aim of this study was to determine whether quantitative pteridine measurement by fluorescence analysis is suitable for age estimation of the adult blow fly Lucilia sericata and thus useful for supporting the entomological determination of the $\mathrm{PMI}_{\text {min. }}$. In addition, the impact of sex and size of the fly head and body on the pteridine level was examined, since the possibility of interference by these factors has been mentioned before $[9,10,17,26,31]$.

Compared to previous studies on L. sericata [e.g. 10], we modified the method in the present study, analyzing a larger number of specimens per age and temperature condition, and applying accumulated degree days (ADD) for age assessment across temperatures.

\section{Materials and methods}

\section{Fly stocks}

A colony of $L$. sericata was established based on field catches and rearing from specimens sampled during autopsies. Adults were kept in $57 \times 38 \times 36 \mathrm{~cm}$ rearing cages, provided with sugar and water ad libitum at room temperature $\left(20{ }^{\circ} \mathrm{C} \pm\right.$ $2{ }^{\circ} \mathrm{C}$ ) and a 12:12 light dark cycle. Once a week, a piece of 
beef liver ( $\sim 5 \mathrm{~g})$ was provided as a source of protein and as an oviposition medium for maintaining the stock.

\section{Producing the age cohorts}

$24 \mathrm{~h}$ after oviposition on the beef liver, the newly hatched larvae were transferred on to minced meat, consisting of half beef and half pork. Plastic cups containing $40 \mathrm{~g}$ minced meat and about 40 larvae were placed in cubic plastic containers $(10.5 \times 10.5 \times 8 \mathrm{~cm})$. The bottom of the plastic container was covered with wood shavings, which served as medium for pupariation. The container was closed with a lid that had tiny air holes to allow oxygen to enter while preventing the larvae from escaping during the migration phase. The containers were incubated at $16^{\circ}$ or $25^{\circ} \mathrm{C}$ untill pupariation.

Starting at day 10 after oviposition, the containers were checked daily for pupae. Day 10 was chosen because it marks the middle point between the beginning of the migration phase and the hatching of the first flies at $25{ }^{\circ} \mathrm{C}$, which was the experimental temperature that resulted in the fastest development. The pupae were transferred into screw top glasses, the lids of which were also provided with air holes. Access for a $10 \mathrm{ml}$ syringe was provided in the middle of the lid (Fig.1). This hole allowed for the supply of water, food or the relocation of specimens, while minimizing the risk of adult escape.

Pupae were checked every $24 \mathrm{~h}$ for fly eclosion and hatched flies were separated on a daily basis to minimize age variations within a study group. Groups of 25-30 flies were kept in the dark, at two constant temperatures each $\left(16^{\circ}\right.$ or $\left.25^{\circ} \mathrm{C}\right)$ with sugar and water ad libitum. Samples of $5-10$ flies were removed at the age of $0(<24 \mathrm{~h}), 5,10,15,20$

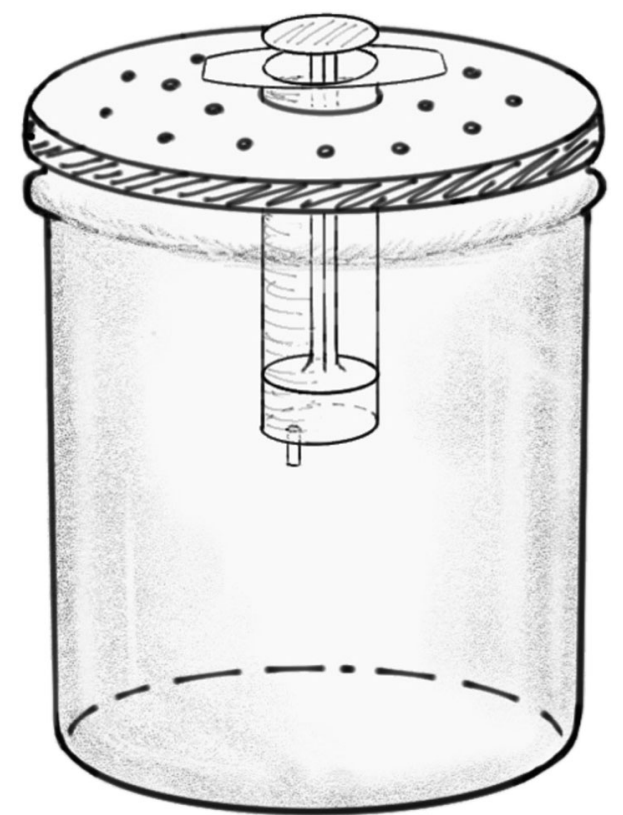

Fig. 1 Screw top glass as used for the experiment; the lid is provided with air holes and a hole for a $10 \mathrm{ml}$ syringe and 25 days respectively and killed by freezing at $-20{ }^{\circ} \mathrm{C}$. These specimens were then stored at the same temperature. By repeating this procedure three times, a total of about 25 flies per sex, age and temperature were obtained, aiming for a balanced number between the sexes.

\section{Processing and measurement}

The fly head was separated from the body and transferred into a $1.5 \mathrm{ml}$ micro tube. It was ground with a pestle in $500 \mu \mathrm{l}$ of $0.05 \mathrm{M}$ Tris-HCl-Buffer ( $\mathrm{pH} 8.0$ ) to facilitate the dissolution of the water soluble pteridines in buffer. Tubes were centrifuged for $5 \mathrm{~min}$ at $6000 \mathrm{~g}$, then $150 \mu \mathrm{l}$ of the supernatant was transferred into a well of a 96-well microplate. The measurement of the pteridine concentration was modified according to Zhu et al. [18], using fluorescence intensity after stimulation. The pteridine fluorescence was measured in a microplate reader (Tecan, Infinite M200) at an emission wavelength of $450 \mathrm{~nm}$ after excitation with $360 \mathrm{~nm}$. The intensity of the emitted light is given in relative fluorescence units (RFU). As a reference for adult fly size, the length of the posterior cross vein $[32,33]$ of the right wing, and the head width (widest point), were measured on an image captured with an AxioCamICc1 through a binocular microscope. Axio Vision 4.7.1 (08/2008) was used for measurements and graph paper was used as a size reference for calibration. Pteridine RFU values were then plotted against fly size and sex.

Heads and pteridine solutions were stored and processed in a frozen or cooled state at any time, except during measurement of the fluorescence which was being performed at room temperature. The samples were protected from direct light by aluminum foil.

\section{Accumulated degree days (ADD)}

In order to quantify ageing across temperatures we use the concept of accumulated degree days (ADD). ADD measures the accumulated thermal energy given to an insect as temperature over time (days) and serves as a parameter of physiological age, mostly independent of the temperature conditions during rearing [5].

The formula for summing the accumulated temperature is as follows:

$\mathrm{ADD}=\left(\mathrm{T}-\mathrm{T}_{0}\right) \mathrm{x}$ age in days

$\mathrm{T}$ : mean ambient temperature.

$\mathrm{T}_{0}$ : lower threshold temperature $9{ }^{\circ} \mathrm{C}[5,34-36]$.

\section{Statistical analysis}

Pteridine values of the different repetitions were examined according to their sex for differences between the groups 
using a t-test. Pooling of repeated groups only took place if no significant difference $(p>0.05)$ could be detected. The examination of the minimum and maximum values for outliers was carried out with the Dean Dixon test after confirmation of the normal distribution (Kolmogorov-Smirnov test).

A correlation between head width or length of the posterior cross vein and pteridine RFU value was analyzed using Pearson's correlation coefficient. The calculations were carried out with Excel.

\section{Mock case}

In order to test the applicability of the method for age determination of flies in real cases, a mock case with 5 flies per age group and 3 age groups per temperature $\left(16{ }^{\circ} \mathrm{C}\right.$ and $\left.25^{\circ} \mathrm{C}\right)$ was set up. The true age of the fly was unknown to the person carrying out the test. The measured pteridine level was compared with that of the groups of the known age (same sex) and a minimum age of the fly was determined using the generated reference data.

\section{Results}

Fluorescence level and thus the extracted pteridine from the heads of $L$. sericata showed a logarithmic increase with rising ADD (Fig. 2). The comparison of flies $<70$ ADD with flies $>70$ ADD showed a significant difference between these groups, as did the comparison of flies with an age of $<5$ days, 5-10 days and $>10$ days within one temperature. Next to age $(p<0.05)$, the sex of the fly showed a significant influence $\left(p<4.09 \times 10^{-6}\right)$ on pteridine levels (Figs. 2 and 3). Male flies achieved higher fluorescence values than females, while they were smaller in size. No significant relationship between size $\left(\mathrm{r}=-1.4 \times 10^{-9}\right)$ of the fly and the measured pteridine level could be determined (Fig. 4).

Based on the arithmetic mean of each group of the same age and sex $(n=16-25)$, the increase of pteridine can be described by the following formulas: $y=267.05 \ln (x)-46.988$

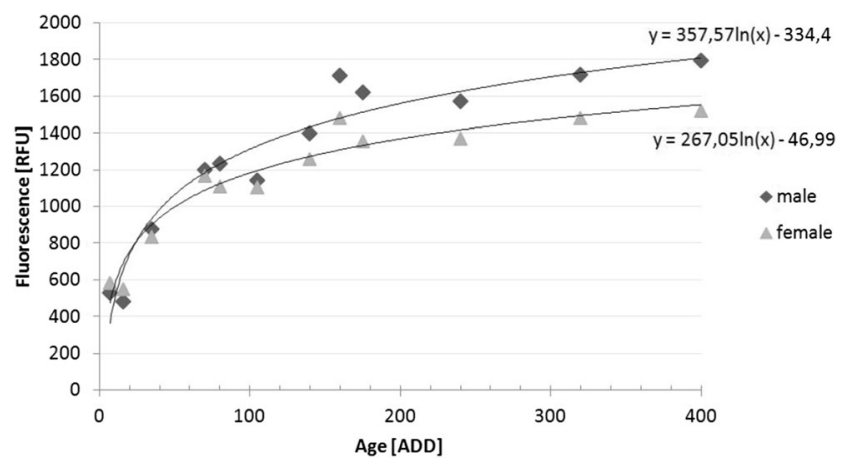

Fig. 2 Mean fluorescence values separated by sex for the respective ADD ( $n=16-25$ per sampling, both rearing temperatures combined)

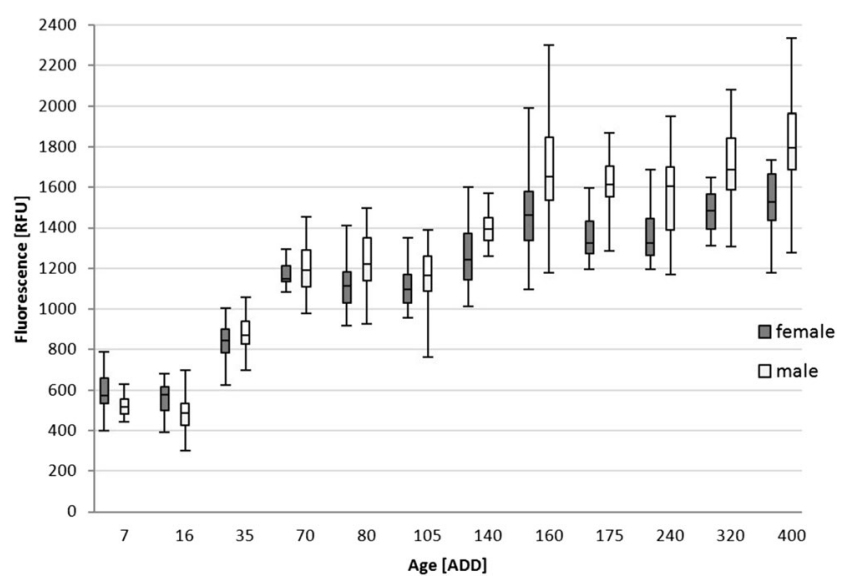

Fig. 3 Box plots of the fluorescence values separated by sex for the respective ADD $(n=16-25$ each per sampling, both rearing temperatures combined) where the dividing line of the box indicates the median and the end of the whiskers the maximum and minimum value; outliers are excluded

(female) and $y=357.57 \ln (x)-334.4$ (male, Fig. 2), considering the two rearing temperatures together. Despite the fact that pteridine values are considered to be temperature-dependent [17-19], both applied temperatures showed similar approximate curves after transforming age in ADD (Fig. 5).

The comparison of the estimated minimum age (based on the fluorescence level) with the true age of the flies in the mock case demonstrated that an overestimation of the real age in ADD only occurred in two out of 30 samples (sample 4 and 5 of group A, age was $<24$ h each) (Table 1). However, with increasing age, there was an increasing discrepancy between the true and estimated age, while the minimum age should always be below the real age.

\section{Discussion}

Until now, forensic entomology ran the risk that the calculated $\mathrm{PMI}_{\min }$, although correct, would be significantly different to the actual time since death when empty puparia were present as it is unclear when the adult fly left the puparium; it could be hours, days, weeks or months prior collection of the specimens (see [37] for discussion about ageing the chemical degradation of empty puparia). By assuming that the fly hatched immediately before the puparium was found, the $\mathrm{PMI}_{\min }$ correctly takes this possible delay into account. Nevertheless, it is still possible that there is a loss of information in this scenario. Hence, for estimating the age of adult flies a parameter like the pteridin level in the fly's eye could be useful.

A positive correlation between pteridine levels and age has been detected in most insects that have been studied, including many adult Diptera, with differences just in the pattern of increase depending on the species. While the flies Musca domestica [17], Chrysomya bezziana [19], Calliphora vicina 

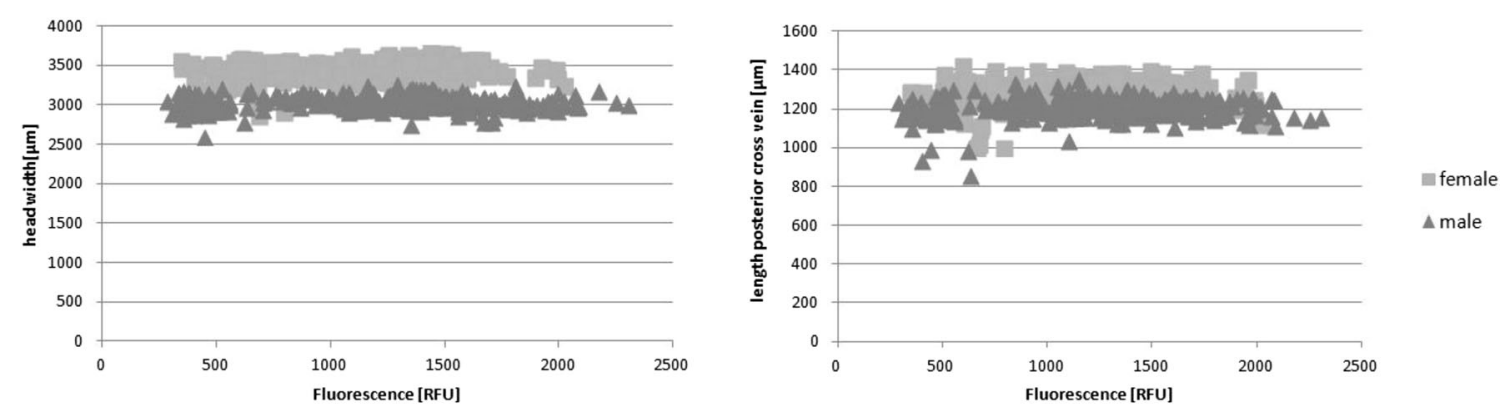

Fig. 4 Correlation of fluorescence values and head width $\left(\mathrm{r}=-1.6 \times 10^{-9}\right)$ or fly size $\left(\mathrm{r}=-1.4 \times 10^{-9}\right)$

[8], Chrysomya megacephala, Cochliomyia macellaria and Phormia regina [27] (with the exception of $P$. regina reared at $5.4{ }^{\circ} \mathrm{C}$ showing a linear increase), Anastrepha ludens [38] as well as Lucilia sericata [10] show a curvilinear increase of pteridine with age, the Diptera Chrysomya megacephala [18], Boettcherisca peregrina [6] and Glossina spp. [20] show a linear increase. In other insects such as the honey bee Apis mellifera [39] a correlation between ageing and pteridine level was also found, while, for example, the ants Polyrhachis sexspinosa [40] and Platythyrea punctata [41] showed no direct correlation.

Pteridine is currently attributed three main tasks in relation to insects: To act as a filter for UV light [25, 26], as pigmentation, and as a form of nitrite excretion [42]. Assuming that in the eye of the fly its function as a filter is predominant would explain the logarithmic increase due to an adjustment of the pteridine synthesis as soon as the concentration necessary for protection has been reached. If the increase in pteridine is mainly due to the excretion of nitrates [22], a linear increase would be more likely based on the assumption of a continuous production. As diet $[10,17,19]$, light intensity and duration [26] as well as movement [17] have no influence on the pteridine value, which would have to be the case if pteridines were a pure degradation or excretion product and thus had to correlate with activity and metabolic rate, the assumption that pteridines are simply excretion products should be rejected. Furthermore, no correlation of fly size, indicated by vein length or head width, on the pteridine value could be demonstrated (Fig. 4). This finding contradicts previous observations concerning $L$. sericata, showing a significant correlation of fly size and pteridine level [10]. Further

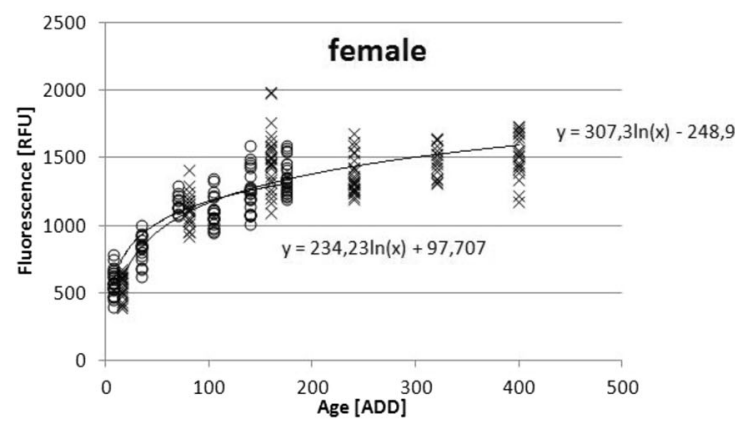

Fig. 5 Fluorescence values separated by sex and temperature information on influencing factors could maybe be provided by testing pupae and larvae; the latter has shown a linear increase of pteridine with larval age in blow flies $C h$. megacephala and Ch. rufifacies [43].

The present study confirmed a positive curvilinear relationship between the age of the examined fly species and the measured fluorescence value, i.e. the pteridine-level as mentioned before by Wall et al. [10] for L. sericata. After 70-80 ADD the increase slows down and the curve approaches a maximum value and some sort of saturation. Hence, age determination of $L$. sericata on the basis of pteridine levels seems to be limited to a physiological age of about 70 ADD. For older specimens, only the indication of a minimum age of about $>70$ ADD is possible. The mock case also confirmed this limitation of age determination up to 70-80 ADD of the adult fly. Nevertheless, by using the fluorescence value it was possible to determine a minimum age, which was never above the actual age. Male flies, which can be easily recognized by their holoptic eyes, overall exhibited a higher pteridine level than female flies. This phenomenon has been observed in other fly species before $[17,19,26]$, but as yet no explanation for this has been provided. For forensic purposes this must be taken into account; the sex of the fly determines which of the two developed formulas must be used for age calculation.

Pteridine approached a stable level at around 140-160 ADD (Fig. 5) after eclosion of the adult fly, which coincides with previous observations in Calliphora vicina (there: C. erythrocephala) [26] and restricts the use of quantitative pteridine fluorescence for age determination of adult flies to this period, which covers approximately half the life of a fly

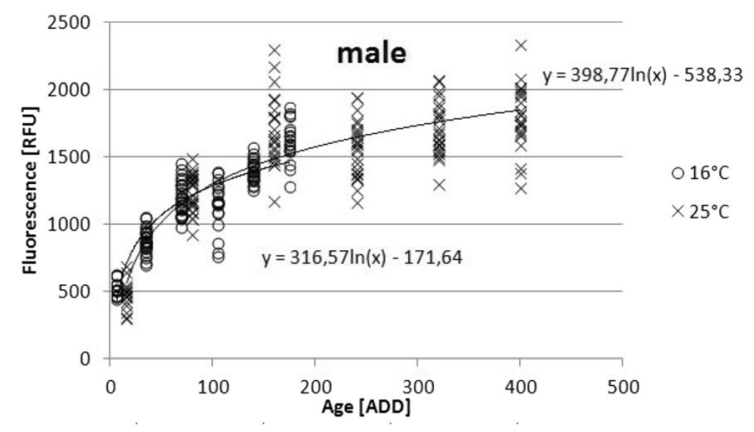


Table 1 Comparison of the estimated minimum age (based on the fluorescence level) in the mock case with the real age of the fly

\begin{tabular}{|c|c|c|c|c|c|c|c|c|}
\hline \multirow[t]{2}{*}{ Group } & \multirow[t]{2}{*}{ Sample } & \multirow[t]{2}{*}{ Temperature } & \multirow[t]{2}{*}{ Fluorescence value } & \multirow[t]{2}{*}{ Sex } & \multicolumn{2}{|c|}{ Age } & \multicolumn{2}{|c|}{ estimated minimum Age } \\
\hline & & & & & {$[\mathrm{d}]$} & {$[\mathrm{ADD}]$} & {$[\mathrm{d}]$} & {$[\mathrm{ADD}]$} \\
\hline \multirow[t]{5}{*}{ A } & 1 & 16 & 380 & $\mathrm{f}$ & $\leq 1$ & 7 & $\leq 1$ & 7 \\
\hline & 2 & 16 & 420 & $\mathrm{f}$ & $\leq 1$ & 7 & $\leq 1$ & 7 \\
\hline & 3 & 16 & 397 & $\mathrm{f}$ & $\leq 1$ & 7 & $\leq 1$ & 7 \\
\hline & 4 & 16 & 355 & $\mathrm{~m}$ & $\leq 1$ & 7 & $\leq 1$ & 16 \\
\hline & 5 & 16 & 333 & $\mathrm{~m}$ & $\leq 1$ & 7 & $\leq 1$ & 16 \\
\hline \multirow[t]{5}{*}{ B } & 1 & 16 & 749 & $\mathrm{f}$ & 10 & 70 & $\leq 1$ & 7 \\
\hline & 2 & 16 & 686 & $\mathrm{f}$ & 10 & 70 & $\leq 1$ & 7 \\
\hline & 3 & 16 & 764 & $\mathrm{~m}$ & 10 & 70 & 5 & 35 \\
\hline & 4 & 16 & 712 & $\mathrm{~m}$ & 10 & 70 & 5 & 35 \\
\hline & 5 & 16 & 713 & $\mathrm{~m}$ & 10 & 70 & 5 & 35 \\
\hline \multirow[t]{5}{*}{$\mathrm{C}$} & 1 & 16 & 864 & $\mathrm{f}$ & 20 & 140 & 5 & 35 \\
\hline & 2 & 16 & 919 & $\mathrm{f}$ & 20 & 140 & 5 & 35 \\
\hline & 3 & 16 & 1032 & $\mathrm{~m}$ & 20 & 140 & 5 & 35 \\
\hline & 4 & 16 & 781 & $\mathrm{~m}$ & 20 & 140 & 5 & 35 \\
\hline & 5 & 16 & 843 & $\mathrm{~m}$ & 20 & 140 & 5 & 35 \\
\hline \multirow[t]{5}{*}{ D } & 1 & 25 & 1335 & $\mathrm{f}$ & 10 & 160 & 5 & 80 \\
\hline & 2 & 25 & 997 & $\mathrm{~m}$ & 10 & 160 & 5 & 35 \\
\hline & 3 & 25 & 1034 & $\mathrm{~m}$ & 10 & 160 & 5 & 35 \\
\hline & 4 & 25 & 1213 & $\mathrm{~m}$ & 10 & 160 & 5 & 70 \\
\hline & 5 & 25 & 1297 & $\mathrm{~m}$ & 10 & 160 & 5 & 70 \\
\hline \multirow[t]{5}{*}{ E } & 1 & 25 & 1339 & $\mathrm{f}$ & 15 & 240 & 5 & 80 \\
\hline & 2 & 25 & 1398 & $\mathrm{f}$ & 15 & 240 & 5 & 80 \\
\hline & 3 & 25 & 1237 & $\mathrm{f}$ & 15 & 240 & 5 & 70 \\
\hline & 4 & 25 & 1450 & $\mathrm{f}$ & 15 & 240 & 10 & 140 \\
\hline & 5 & 25 & 1027 & $\mathrm{~m}$ & 15 & 240 & 5 & 35 \\
\hline \multirow[t]{5}{*}{$\mathrm{F}$} & 1 & 25 & 1424 & $\mathrm{f}$ & 25 & 400 & 10 & 140 \\
\hline & 2 & 25 & 1121 & $\mathrm{f}$ & 25 & 400 & 5 & 70 \\
\hline & 3 & 25 & 1022 & $\mathrm{f}$ & 25 & 400 & 5 & 80 \\
\hline & 4 & 25 & 1727 & $\mathrm{~m}$ & 25 & 400 & 10 & 160 \\
\hline & 5 & 25 & 1655 & $\mathrm{~m}$ & 25 & 400 & 10 & 160 \\
\hline
\end{tabular}

[44]. Nevertheless, even such a short and restricted period of time would already mean an improvement for the $\mathrm{PMI}_{\min }$ estimation, since a wider range than just the time taken by juvenile development and metamorphosis could be covered by adding the age of the adult fly.

Pteridine fluorescence analysis of dead flies collected at the site is another possibility that could be explored in the future as there is a clear gap of knowledge when it comes to pteridine stability and half-life, for example due to photosensitivity. Even though pteridine is considered photosensitive in vitro, it was stable in vivo $[21,26]$, which applied not only to living animals but also to freeze-dried heads, making it easy to store and meaning immediate processing was not required.

Comparing the two temperatures $\left(16^{\circ} \mathrm{C}\right.$ and $\left.25^{\circ}\right)$ with their respective $\mathrm{ADD}$ (Fig. 5), an almost congruent pattern can be seen in the common course (illustrated by the approximation). In order to compare the patterns over its entire length it would be necessary to collect samples of older flies at $16{ }^{\circ} \mathrm{C}$ to add higher ADD values for this temperature. In addition, it seems advisable to analyze more temperature profiles to get a more accurate picture of the fluorescence progression, especially within the relevant range up to 70 ADD. Nevertheless, the logarithmic shape can be seen clearly in both curves as well as their associated maximum value of pteridine. The scattering of the fluorescence values within a temperature group results in an increasing overlap of ranges with increasing $\mathrm{ADD}$, making it impossible to clearly assign a fluorescence value to a distinct age. But considering the rising mortality of flies with increasing ADD [45], the lower ADD ranges also seem to be the more relevant for everyday application.

Last but not least it should be mentioned that even if the age of the adult fly is successfully estimated, its previous development on the body must be ensured. It could have developed on 
site or it could have arrived as imago from outside. This problem restricts the use of this method to indoor cases. If there is a large number of flies, belonging to the same age cohort and the corresponding species is represented by several empty puparia at the place of discovery, it is likely that they have developed on site [8]. To estimate whether a fly has developed on site or may just have entered from outside, for example 1 day before sampling, wing fray analysis and determination of sex ratios could also provide an indication of the origin of present flies, where a greater amount of wing damage as well as a female dominance hint at flies that entered from outdoors [46]. This indicates that the combination of different methods could help to improve the interpretation of entomological evidence. In the future, stable isotope analysis might also prove to be a useful tool for associating flies with a food source [47].

Altogether, the quantitative pteridine fluorescence provides a good approach to age determination of adult $L$. sericata within the first days after hatching. Apart from age and sex, no further factors seem to influence the fluorescence value, which is an advantage compared to other methods.

\section{Key points}

1. The pigment pteridine accumulates in the eyes of Lucilia sericata with increasing age and can be measured by fluorescence spectroscopy.

2. The pteridine level allows conclusions regarding the minimum age of the fly, which can be used to narrow down the post-mortem interval.

3. The concept of accumulated degree days (ADD) was used to quantify ageing across temperatures.

4. While sex and age showed significant influences on the fluorescence value and therefore on the pteridine level, fly size did not.

Funding Open Access funding provided by Projekt DEAL.

Open Access This article is licensed under a Creative Commons Attribution 4.0 International License, which permits use, sharing, adaptation, distribution and reproduction in any medium or format, as long as you give appropriate credit to the original author(s) and the source, provide a link to the Creative Commons licence, and indicate if changes were made. The images or other third party material in this article are included in the article's Creative Commons licence, unless indicated otherwise in a credit line to the material. If material is not included in the article's Creative Commons licence and your intended use is not permitted by statutory regulation or exceeds the permitted use, you will need to obtain permission directly from the copyright holder. To view a copy of this licence, visit http://creativecommons.org/licenses/by/4.0/.

\section{References}

1. Amendt J, Campobasso CP, Gaudry E, Reiter C, LeBlanc HN, Hall MJR. Best practice in forensic entomology - standards and guidelines. Int J Legal Med. 2007;121:90-104.
2. Iacovou M. The living arrangements of elderly Europeans. ISER Working Paper Series. 2000; No. 2000-09.

3. Vespa J. Historical living arrangements of older adults: 1967-2016. US Census Bureau 2017. https://www.census.gov/content/dam/ Census/library/working-papers/2017/demo/SEHSD-WP2017-30. pdf. .

4. Bhadra P, Hart AJ, Hall MJR. Factors affecting accessibility to blowflies of bodies disposed in suitcases. Forensic Sci Int. 2014;239:62-72.

5. Reibe S, Doetinchem P, Madea B. A new simulation-based model for calculating post-mortem intervals using developmental data for Lucilia sericata (Dipt.: Calliphoridae). Parasit Res. 2010;107:9-16.

6. Zhu GH, Ye GY, Li K, Hu C, Xu XH. Determining the age of adult flesh flies, Boettcherisca peregrina, using pteridine fluorescence. Med Vet Entomol. 2013;27:59-63.

7. Greenberg B. Flies as forensic indicators. J Med Entomol. 1991;28: 565-77.

8. Bernhardt V, Hannig L, Kinast R, Verhoff M, Rothweiler F, Zehner $\mathrm{R}$, et al. Quantitative pteridine fluorescence analysis: a possible agegrading technique for the adult stages of the blow fly Calliphora vicina (Diptera: Calliphoridae). J Insect Physiol. 2017;98:356-9.

9. Hayes EJ, Wall R. Age-grading adult insects: a review of techniques. Physiol Entomol. 1999;24:1-10.

10. Wall R, Langley PA, Morgan KL. Ovarian development and pteridine accumulation for age determination in the blow fly Lucilia sericata. J Physiol. 1991;37:863-8.

11. Bala M, Sharma A. Review of some recent techniques of age determination of blow flies having forensic implications. Egypt $\mathbf{J}$ Forensic Sci. 2016;6:203-8.

12. Goodrich BS. Cuticular lipids of adults and puparia of the Australian sheep blowfly Lucilia cuprina. J Lipid Res. 1970;11:1-6.

13. Bernhardt V, Pogoda W, Verhoff M, Toennes S, Amendt J. Estimation the age of the adult stages of the blow flies Lucilia sericata and Calliphora vicina (Diptera: Calliphoridae) by means of the cuticular hydrocarbon n-pentacosane. Sci Justice. 2017;57: 361-5.

14. Desena ML, Edman JD, Clark JM, Symington SB, Scott TW. Aedes aegypti (Diptera: Culicidae) age determination by cuticular hydrocarbon analysis of female legs. J Med Entomol. 1999;36: 824-30.

15. Neville AC. Daily cuticular growth layers and the teneral stage in adult insects: a review. J Insect Physiol. 1982;29:211-9.

16. Burkhard DU, Ward PI, Blanckenhorn WU. Using age grading by wing injuries to estimate size-dependent adult survivorship in the field: a case study of the yellow dung fly Scathophaga stercoraria. Ecol Entomol. 2002;27:514-20.

17. McIntyre GS, Gooding RH. Pteridine accumulation in Musca domestica. J Insect Physiol. 1994;41:357-68.

18. Zhu GH, Ye GY, Hu C. Determining the adult age of the oriental latrine fly, Chrysomya megacephala (Fabricus) (Diptera: Calliphoridae) by pteridine fluorescence analysis. Entomol Sin. 2003;10:245-55.

19. Wall R, Langley PA, Stevens J, Clarke GM. Age-determination in the old-world screw-worm fly Chrysomya bezziana by pteridine fluorescence. J Insect Physiol. 1990;36:213-8.

20. Langley PA, Hall MJR, Felton T. Determining the age of tsetse flies, Glossina spp. (Diptera: Glossinidae): an appraisal of the pteridine fluorescence technique. Bull Entomol Res. 1988;78:387-95.

21. Ziegler I, Harmsen R. The biology of pteridines in insects. Adv Insect Physiol. 1970;6:139-203.

22. Ziegler I. Pterine: Pigmente, Cofaktoren und Signalverbindungen bei der zellulären Interaktion. Naturwissenschaften. 1987;74:56372.

23. Martínez A, Barbosa A. Are pterins able to modulate oxidative stress? Theor Chem Accounts. 2010;127:485-92. 
24. Thörig EW, Heinstra PWH, Klarenberg AJ, Eisses KT, van Kooten $\mathrm{H}$, Scharloo W. Multiple functions of pteridines in drosophila. Specific fluorescent patterns in three sibling species. Genetica. 1981;56:153-60.

25. Hoffmann C, Langer H. Die spektrale Augenempfindlichkeit der Mutante „chalky“ von Calliphora erythrocephala. Naturwissenschaften. 1961;48:605.

26. Patat U. Über das Pteridinmuster der Facettenaugen von Calliphora erythrocephala. Ein Beitrag zur Funktion und Stabilität der Pterine. Z vgl Physiol. 1965;51:103-34.

27. Cammack JA, Reiskind MH, Guisewite LM, Denning SS, Watson DW. Quantifying pteridines in the heads of blow flies (Diptera: Calliphoridae): application for forensic entomology. Forensic Sci Int. 2017;280:44-8.

28. Hayes EJ, Wall R, Smith KE. Measurement of age and population age structure in the blowfly, Lucilia sericata (Meigen) (Diptera: Calliphoridae). J Insect Physiol. 1998;44:895-901.

29. Fremdt H, Amendt J. Species composition of forensically important blow flies (Diptera: Calliphoridae) and flesh flies (Diptera: Sarcophagidae) through space and time. Forensic Sci Int. 2014;236:1-9.

30. Lutz L, Verhoff MA, Amendt J. Environmental factors influencing flight activity of forensically important female blow flies in Central Europe. Int J Legal Med. 2018;133:1267-78.

31. Taira T, Nawa S. A note on pigmentation in the eye. Drosoph Inf Serv. 1959;33:167.

32. Clark K, Evans L, Wall R. Growth rates of the blowfly, Lucilia sericata, on different body tissues. Forensic Sci Int. 2006;156: 145-9.

33. Ireland S, Turner B. The effects of larval crowding and food type on the size and development of the blowfly, Calliphora vomitoria. Forensic Sci Int. 2005;159:175-81.

34. Marchenko MI. Medicolegal relevance of cadaver entomofauna for the determination of the time of death. Forensic Sci Int. 2001;120: 89-109.

35. Niederegger S, Pastuschek J, Mall G. Preliminary studies of the influence of fluctuating temperatures on the development of various forensically relevant flies. Forensic Sci Int. 2010;199:72-8.

36. Shiravi AH, Mostafavi R, Akbarzadeh K, Oshaghi MA. Temperature requirements of some common forensically important blow and flesh flies (Diptera) under laboratory conditions. J Arthropod Borne Dis. 2011;5:54-62.
37. Moore HE, Pechal JL, Benbow ME, Drijfhout FP. The potential use of cuticular hydrocarbons and multivariante analysis to age empty puparial cases of Calliphora vicina and Lucilia sericata. Sci Rep. 2017;7:1933.

38. Tomic-Carruthers N, Robacker DC, Mangan RL. Identification and age-dependance of pteridines in the head of adult Mexican fruit fly Anastrepha ludens. J Insect Physiol. 1996;42:359-66.

39. Rinkevich FD, Margotta JW, Pittman JM, Ottea JA, Healy KB. Pteridine levels and head weights are correlated with age and colony task in the honey bee Apis mellifera. Peer J. 2016;4:e2155.

40. Robson SKA, Crozier RH. An evaluation of two biochemical methods of age determination in insects (pteridines and lipofuscins) using the ant Polyrhachis sexpinosa latrielle (Hymenoptera: Formicidae). Aust J Entomol. 2009;48:102-6.

41. Hartmann C, Heinze J, Bernadou A. Age-dependent changes in cuticular color and pteridine levels in a clonal ant. J Insect Physiol. 2019;118:103943.

42. Harmsen R. The excretory role of pteridine in insects. J Exp Biol. 1966;45:1-13.

43. Roziah A, Rostlawatt R, Nazni WA, Norazizah A, Khairul Asuad M, Lee HL. Pteridine fluorescence in age-determination of immature Chrysomya megacephla (Fabricius) and Chrysomya rufifacies (Macquart) (Diptera: Calliphoridae). Trop Biomed. 2019;36:48894.

44. Wall R. The reproductive output of the blowfly Lucilia sericata. J Insect Physiol. 1993;39:743-50.

45. Hayes EJ, Wall R, Smith KE. Mortality rate, reproductive output, and trap response bias in populations of the blowfly Lucilia sericata. Ecol Entomol. 1999;24:300-7.

46. Beutler M, Hart A, Hall MJR. The use of wing fray and sex ratios to determine the origin of flies at an indoor crime scene. Forensic Sci Int. 2020;307:110104.

47. Bernhardt V, Holdermann T, Scheid N, Schäfer T, Verhoff MA, Amendt J. Same, same but different! - matching entomological traces to a human food source by stable isotope analysis. Int $\mathrm{J}$ Legal Med. 2018;132:915-21.

Publisher's note Springer Nature remains neutral with regard to jurisdictional claims in published maps and institutional affiliations. 